\title{
Analisa Pressure dan Level pada Plant CE33 Electronic Process Control Berbasis PID
}

\author{
Andi Hartanto ${ }^{1 *}$, Kamarudin ${ }^{1}$ \\ ${ }^{1}$ Politeknik Negeri Batam, Jurusan Teknik Elektro, Batam \\ *E-mail: andihartanto@polibatam.ac.id
}

\begin{abstract}
Abstrak
Penelitian ini mencakup proses pengukuran, pembacaan, dan analisa pressure dan leve/ pada plant CE33 Electronic Process Control. Di dalam penelitian ini dimulai dengan melakukan kalibrasi sensor yang digunakan untuk mendapatkan hasil pembacaan pressure dan level yang baik. Pengendali yang memiliki performansi yang baik diperoleh dengan memberikan parameter tuning pengendali yang akurat. Tuning parameter pengendali adalah proses mengatur parameter-parameter pengendali untuk menghasilkan sistem kendali yang diinginkan. Penelitian ini membahas kontrol PID menggunakan Trial \& Error Tuning. Sistem yang dikendalikan disimulasikan menggunakan software LabVIEW sehingga mendapatkan respon sistem yang dikendalikan dimana ketiga nilai $P$, $\mathrm{I}$, dan $\mathrm{D}$ disini digunakan dengan memberi nilai $\mathrm{Kp}=2, \mathrm{Ti}=0,250, \mathrm{Kd}=0,010$ agar mendapatkan proses variabel mencapai setpoint dengan hasil yang baik. Artikel ini diharapkan dapat membantu pemahaman dalam pembelajaran untuk melihat tanggapan berbagai kombinasi parameter dengan variasi masukan yang berbeda.
\end{abstract}

Kata kunci: CE33 Electronic Process Control, pressure, level, PID

\begin{abstract}
This research covers the process of measuring, reading and analyzing pressure and levels in the plant CE33 Electronic Process Control. In this research began with the calibration of sensors used to obtain a good pressure and level reading results. Operators with good performance are obtained by providing accurate control tuning parameters. Tuning the controller parameter is the process of setting control parameters to produce the desired control system. This research discusses the control of PID using Trial \& Error Tuning. Controlled systems are simulated using LabVIEW software so as to obtain a controlled system response where the three values of $P$, $I$ and $D$ here are used by rating $K p=2, T i=0.250, K d=0.010$ to get the process variable to achieve setpoint with good results. This article is expected to help understanding the learning to see the responses to various combinations of parameters with different input variations.
\end{abstract}

Keywords: CE33 Electronic Process Control, pressure, level, PID 


\section{Pendahuluan}

Plant CE33 Electronic Process Control adalah simulator proses industri dan memungkinkan untuk mempelajari kontrol proses kompleksitas yang berbeda. Dasar yang diberikan mencakup tangki, pompa, katup manual, katup otomatis dan semua komponen elektronik dan biasa ditemukan dalam proses industri yang sudah dipasang pada struktur pendukung sehingga dapat merealisasikan rangkaian yang berbeda untuk mensimulasikan situasi industri yang berbeda. Instrumentasi elektronik digunakan untuk mendapatkan sistem kontrol yang berbeda dapat berupa inlet, discharge, split-range, $P, P I, P I D$, feed-back, feed-forward yang diterapkan pada jenis proses utama seperti level, flow-rate, pressure.

Pada kegiatan pratikum akan memahami prosedur pelaksanaan pratikum, memahami dasar teori, kemampuan menggunakan alat dan bahan, kemampuan observasi dan memberikan hasil analisa serta pengamatannya. Melalui kegiatan pratikum dapat mengembangkan keterampilan proses yang menjadi dasar kemampuan pengaplikasian sebenarnya sebagai implementasi industri.

Dengan penelitian "Analisa Pressure dan Level pada Plant CE33 Electronic Process Control Berbasis PID" mencoba untuk penerapan ilmu teori PID menggunakan Trial \& Error Tuning. Hasil yang diharapkan mendapatkan kontrol PID yang tepat sehingga nilai process variable mencapai setpoint dengan cepat dan stabil tanpa ada overshoot.

\section{Metode Penelitian}

Tahapan-tahapan yang akan dilakukan dalam pembuatan "Analisa Pressure dan Level pada Plant CE33 Electronic Process Control Berbasis PID" terdiri dari beberapa bagian. Penelitian akan diawali dengan study literature sesuai dengan plant CE33 Electronic Process Control yang akan dikerjakan. Diantaranya study literatur tentang dasar teori komponen maupun alat yang digunakan dalam penelitian.

Dilanjutkan dengan perancangan alat dimulai dengan perancangan perangkat keras (hardware). Plant CE33 Electronic Process Control berada pada lab RTF1.1 Politeknik Negeri Batam.

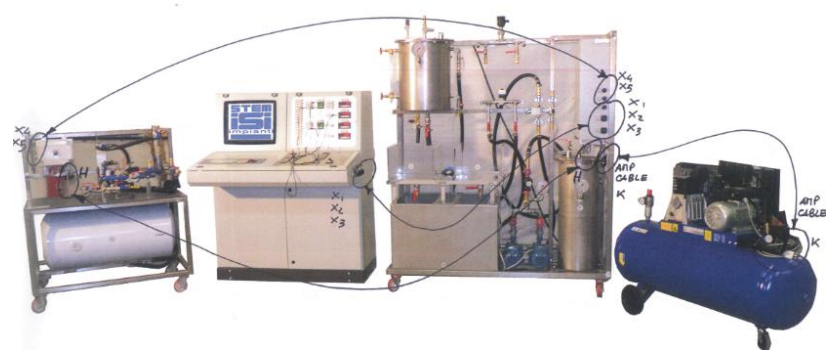

Gambar 1. Plant CE33 Electronic Process Control

Plant CE33 Electronic Process Control ini termasuk opsionalnya ada empat modul, diantaranya:

1. Konsol utama, atau modul kontrol, dimana dapat mengarahkan semua operasi pada tiga modul lainnya.

2. Modul proses

3. Opsional untuk kontrol suhu

4. Opsional untuk kontrol tekanan

Pada penelitian ini modul yang digunakan adalah modul kontrol dan modul proses. Selanjutnya adalah perancangan instalasi listrik yang merupakan rangkaian komponen yang akan digunakan dalam penelitian ini.

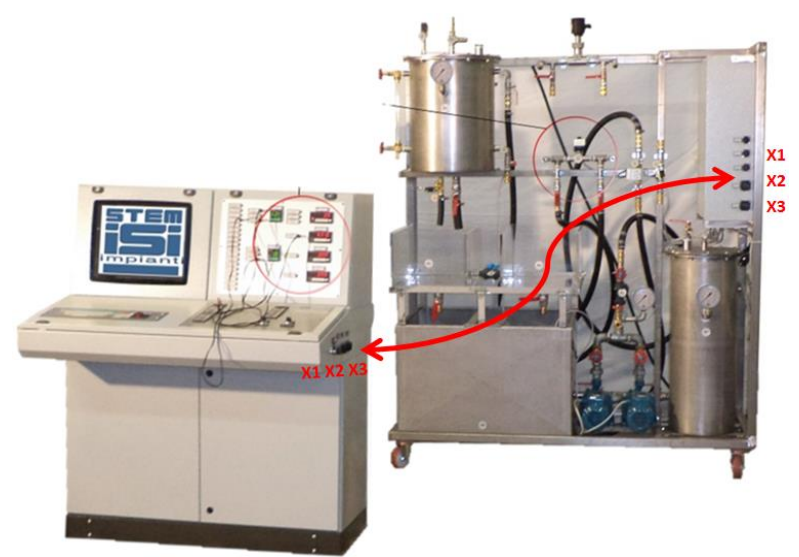

Gambar 2. modul kontrol dan modul proses

Hubungkan semua kabel antara modul proses dan konsol. Semua kabel ditandai di ujungnya dengan pelat menunjukkan konektor yang tepat lalu dihubungkan. Hubung tiap kabel:

- X1: Terhubung antara modul proses dan modul kontrol

- X2: Terhubung antara modul proses dan modul kontrol

- X3: Terhubung antara modul proses dan modul kontrol

- X4: Terhubung antara modul proses dan kontrol proses suhu. 
- X4: Terhubung antara modul proses dan kontrol proses suhu.

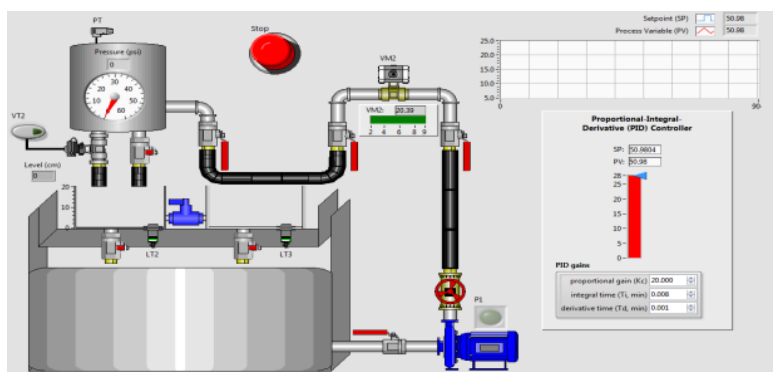

Gambar 3. Tampilan Front Panel menggunakan LabVIEW

Perangkat lunak (Software) dalam penelitian ini menggunakan software LabVIEW dengan USB-6211 National Instruments pada modul kontrol. Pada tampilan LabVIEW disini mengikuti desain pada modul proses plant CE33 Electronic Process Control berfokus kepada komponen yang termasuk dalam jalur rangkaian penelitian ini diantaranya motor pompa (P1), katup modulasi (VM2), tangki penerima bertekanan utama (tangki R1), tangki penerima PVC tipe terbuka (tangki R2), katup solenoid twoways (VT2), sensor level (LT2), sensor pressure (PT). Software LabVIEW digunakan untuk melakukan kontrol operasi sistem untuk monitoring semua pengukuran dan operasi kontrol dari parameter terkait.

\section{Hasil dan Diskusi}

Hasil dari teknik pengujian pada penelitian ini dilakukan dengan cara memberikan tekanan yang ingin diuji ke tangki yang akan menampung tekanan lalu diproses hingga menampilkan nilai tekanan pada pembacaan alat ukur tekanan untuk proses preesure control. Pengujian untuk level dilakukan dengan melihat nilai ketinggian pada pembacaan alat ukur melalui saat proses air memasuki tangki. Namun sebelumnya akan dilakukan proses uji untuk pembacaan alat ukur tekanan dan ketinggian terlebih dahulu sehingga hasil pengukuran mendapatkan hasil yang akurat. Berikut adalah kalibrasi nilai tegangan yang terbaca pada Sensor LT2 (V) terhadap Level $(\mathrm{cm})$ menggunakan metode persamaan linear.
Tabel 1. Pengambilan data untuk leve/ dan tegangan sensor

\begin{tabular}{cc}
\hline Sensor LT2 (V) & Level (cm) \\
\hline$-0,549353$ & 0 \\
$-0,470404$ & 1 \\
$-0,371889$ & 2 \\
$-0,270176$ & 3 \\
$-0,174085$ & 4 \\
$-0,076735$ & 5 \\
0,0193675 & 6 \\
0,110324 & 7 \\
0,214269 & 8 \\
0,310705 & 9 \\
0,406565 & 10 \\
0,502052 & 11 \\
0,598899 & 12 \\
0,69773 & 13 \\
0,798181 & 14 \\
0,894808 & 15 \\
0,996207 & 16 \\
1,09135 & 17 \\
1,18634 & 18 \\
1,28562 & 19 \\
1,38567 & 20 \\
\hline &
\end{tabular}

Hasil persamaan linear didapat $y=10,284 x+5,7955$. Rumus ini yang akan digunakan sebagai nilai kalibrasi pembacaan Level (cm) pada tangki R2.

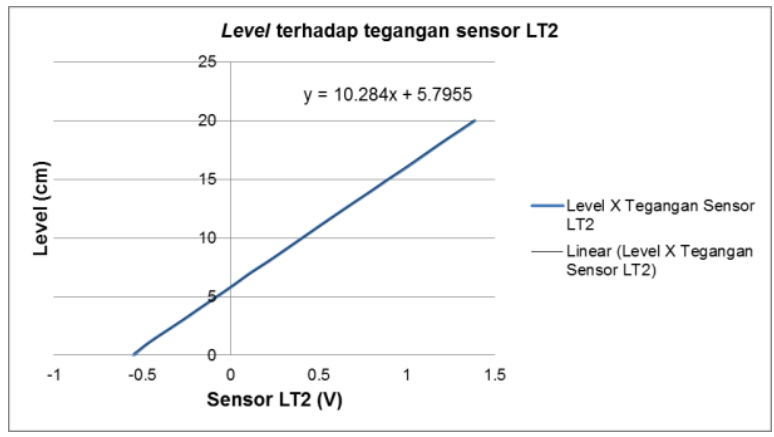

Gambar 4. Grafik persamaan linear level terhadap tegangan sensor

Selanjutnya adalah kalibrasi nilai tegangan yang terbaca pada Sensor PT (V) terhadap Pressure (psi) menggunakan metode persamaan linear. 
Tabel 2. Pengambilan data untuk pressure dan tegangan sensor

\begin{tabular}{|c|c|}
\hline Sensor PT (V) & Pressure (psi) \\
\hline 0,028 & 0 \\
\hline 0,1943 & 1 \\
\hline 0,3606 & 2 \\
\hline 0,5269 & 3 \\
\hline 0,6932 & 4 \\
\hline 0,8595 & 5 \\
\hline 1,0258 & 6 \\
\hline 1,1921 & 7 \\
\hline 1,3584 & 8 \\
\hline 1,5247 & 9 \\
\hline 1,691 & 10 \\
\hline 1,8573 & 11 \\
\hline 2,0236 & 12 \\
\hline 2,1899 & 13 \\
\hline 2,3562 & 14 \\
\hline 2,5225 & 15 \\
\hline 2,6888 & 16 \\
\hline 2,8551 & 17 \\
\hline 3,0214 & 18 \\
\hline 3,1877 & 19 \\
\hline 3,354 & 20 \\
\hline 3,5203 & 21 \\
\hline 3,6866 & 22 \\
\hline 3,8529 & 23 \\
\hline 4,0192 & 24 \\
\hline 4,1855 & 25 \\
\hline 4,3518 & 26 \\
\hline 4,5181 & 27 \\
\hline 4,6844 & 28 \\
\hline 4,8507 & 29 \\
\hline 5,017 & 30 \\
\hline
\end{tabular}

Hasil persamaan linear didapat $y=6,0132 x-0,1684$. Rumus ini yang akan digunakan sebagai nilai kalibrasi pembacaan Pressure (psi) pada tangki R1.

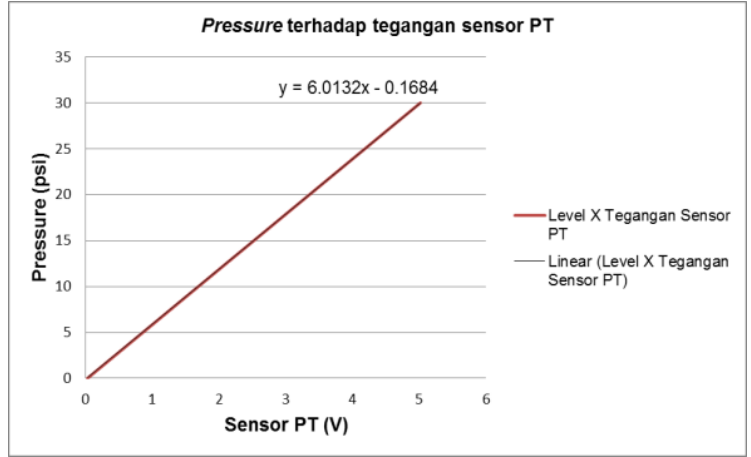

Gambar 5. Grafik persamaan linear pressure terhadap tegangan sensor

Setelah dilakukan proses pengambilan nilai persamaan linear dan dimasukkan kedalam program pada LabVIEW maka didapat nilai error antara pembacaan display pada LabVIEW dan nilai pada kondisi yang terbaca oleh alat ukur yang terpasang pada tangki. Berikut data error yaitu selisih display dan nilai aktual dibandingkan dengan setpoint.

Tabel 3. Nilai error pembacaan sensor LT2

\begin{tabular}{cccc}
\hline $\begin{array}{c}\text { Setpoint } \\
(\mathbf{c m})\end{array}$ & $\begin{array}{c}\text { Display } \\
(\mathbf{c m})\end{array}$ & $\begin{array}{c}\text { Nilai Aktual } \\
(\mathbf{c m})\end{array}$ & $\begin{array}{c}\text { Error } \\
(\%)\end{array}$ \\
\hline 2 & 1,96 & 2 & 0,02 \\
4 & 3,89 & 4 & 0,027 \\
6 & 6,03 & 6 & 0,005 \\
8 & 8,05 & 8 & 0,006 \\
10 & 10,01 & 10 & 0,001 \\
12 & 12 & 12 & 0 \\
14 & 14,08 & 14 & 0,005 \\
16 & 16,15 & 16 & 0,009 \\
18 & 18,2 & 18 & 0,011 \\
20 & 20,13 & 20 & 0,006 \\
\hline
\end{tabular}

Tabel 4. Nilai error pembacaan sensor PT

\begin{tabular}{cccc}
\hline $\begin{array}{c}\text { Setpoint } \\
\text { (psi) }\end{array}$ & $\begin{array}{c}\text { Display } \\
(\mathbf{p s i})\end{array}$ & $\begin{array}{c}\text { Nilai Ak- } \\
\text { tual } \\
(\mathbf{p s i})\end{array}$ & $\begin{array}{c}\text { Error } \\
(\%)\end{array}$ \\
5 & 5 & 5 & 0 \\
10 & 10,02 & 10 & 0,002 \\
15 & 15,13 & 15 & 0,008 \\
20 & 19,98 & 20 & 0,001 \\
25 & 24,93 & 25 & 0,002 \\
30 & 28,87 & 30 & 0,037 \\
\hline
\end{tabular}


Selanjutnya percobaan dengan kontrol PID dengan kondisi manual valve pada tangki R1 dibuka tidak melebihi input air yang masuk kedalam tangki untuk melihat kemampuan kontrol PID yang akan digunakan. Setpoint yang digunakan untuk mendapat kontrol PID adalah setpoint 5 dan didapat hasil grafik Process Variable (PV) atau nilai tekanan yang terbaca terhadap setpoint yang ditentukan.

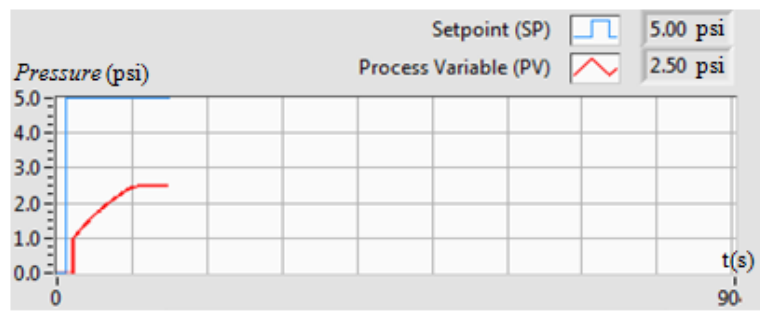

Gambar 6. $\mathrm{Kp}=1, \mathrm{Ti}=0, \mathrm{Td}=0$

Pada tahap pertama pemberian nilai $\mathrm{Kp}$ dengan mengosongkan nilai $\mathrm{Ki}$ dan $\mathrm{Kd}$ untuk melihat apakah tekanan mencapai setpoint yang ditentukan, didapat hasil seperti pada gambar 6 . Tekanan tidak dapat mencapai setpoint yang ditentukan dan berhenti pada nilai 2,5 dan seterusnya.

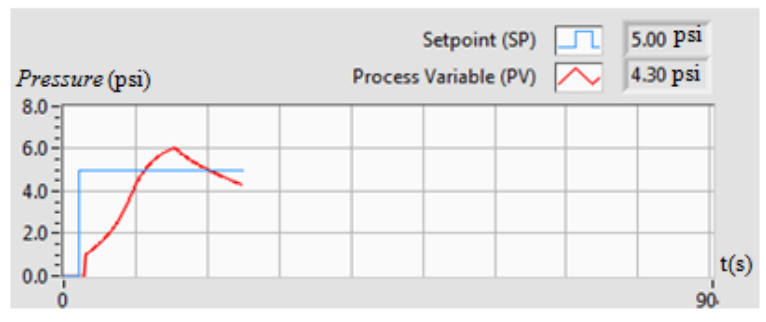

Gambar 7. $\mathrm{Kp}=2, \mathrm{Ti}=0, \mathrm{Td}=0$

Selanjutnya nilai $\mathrm{Kp}$ ditambahkan agar mencapai setpoint yang ditentukan. Disini tekanan bisa mencapai setpoint yang ditentukan tetapi mendapatkan overshoot lalu tekanan terus menurun melebihi setpoint yang ditentukan.



Gambar 8. $\mathrm{Kp}=2, \mathrm{Ti}=0,050, \mathrm{Td}=0$
Maka nilai $\mathrm{Ki}$ ditambahkan menjadi 0,050 . Nilai tekanan disini masih terdapat overshoot tetapi dapat mencapai setpoint tidak turun menjauhi setpoint seperti sebelumnya.

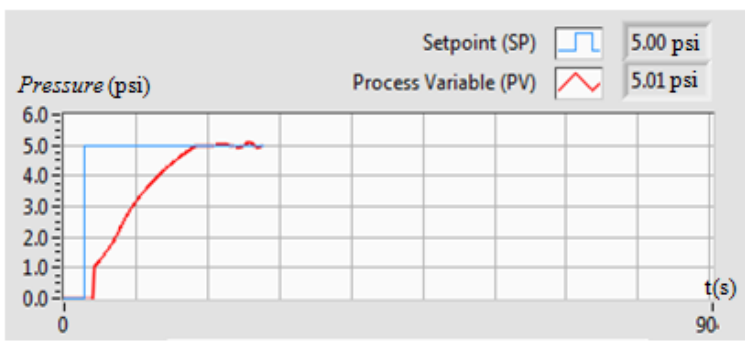

Gambar 9. $\mathrm{Kp}=2, \mathrm{Ti}=0.250, \mathrm{Td}=0$

Nilai Ki sekarang ditambah 0,250 dan dapat dilihat seperti pada gambar 9. Process Variable (PV) atau nilai tekanan yang tebaca tidak mengalami overshoot.

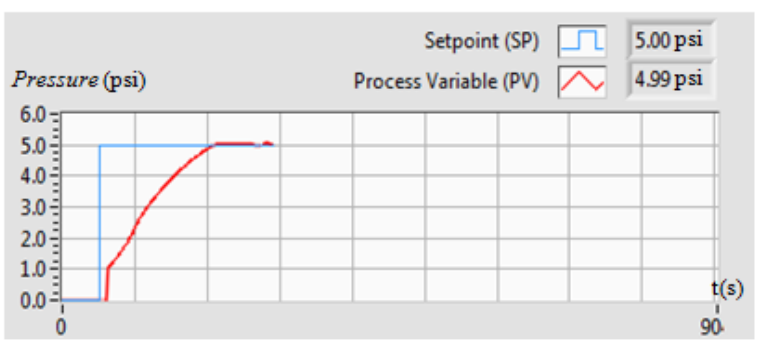

Gambar 10. $\mathrm{Kp}=2, \mathrm{Ti}=0,250, \mathrm{Td}=0,005$

Disini perlu penambahan untuk fungsi nilai $D$ sehingga menggunakan semua fungsi nilai PID. Kd diberikan 0,005 agar nilai tekanan yang mencapai setpoint menjadi stabil. Percobaan selanjutnya dilakukan dengan mengubah nilai setpoint yang diinginkan $(10,15$, 20, dan 25 psi) dengan nilai PID yang telah didapatkan dari hasil percobaan sebelumnya. Dapat dilihat grafik nilai tekanan mencapai setpoint yang ditentukan pada gambar 11 . 


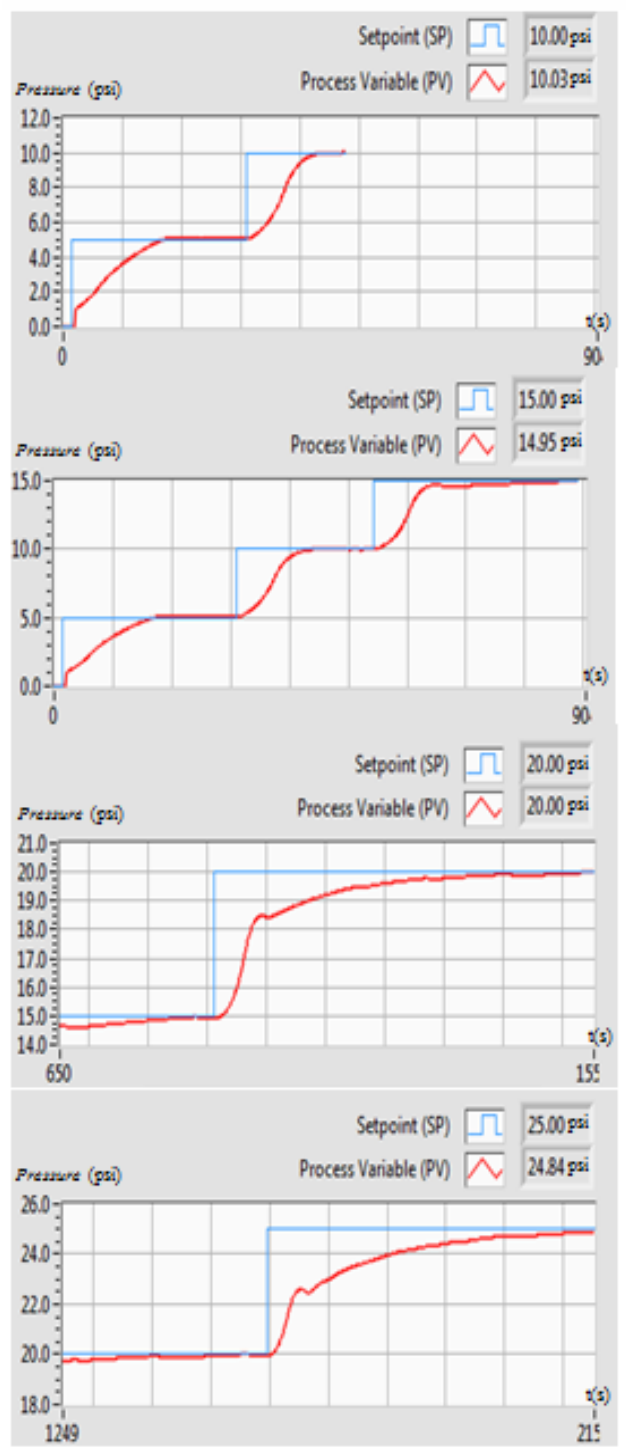

Gambar 11. $\mathrm{Kp}=2, \mathrm{Ti}=0,250, \mathrm{Kd}=0,010$ dengan Setpoint 10 , 15, 20, dan 25 psi

\section{Simpulan}

Nilai kalibrasi pada tiap-tiap komponen memperoleh hasil persamaan linear $\mathrm{y}=10,284 \mathrm{x}+5,7955$ yang akan digunakan sebagai nilai kalibrasi pembacaan Level $(\mathrm{cm})$ pada tangki $\mathrm{R} 2$ dan hasil persamaan linear $\mathrm{y}=6,0132 \mathrm{x}-0,1684$ yang akan digunakan sebagai nilai kalibrasi pembacaan Pressure (psi) pada tangki R1. Pada percobaan kontrol pressure menggunakan Labview, kontrol yang paling baik yaitu dengan menggunakan seluruh nilai dari kontrol PID. Penambahan nilai Td diperlukan karena spesifikasi motor valve yang digunakan memiliki respon yang lambat, konstanta Td dapat meningkatkan stabilitas 18 sistem. Nilai konstanta $\mathrm{Kp}=2, \quad \mathrm{Ti}=0,250$, $\mathrm{Kd}=0,010$ menghasilkan grafik respon cukup baik.

\section{Ucapan Terima Kasih}

Ucapan terima kasih disampaikan kepada Politeknik Negeri Batam, Jurusan Teknik Elektro, Program Studi Teknik Instrumentasi yang telah menyediakan tempat dan kepada tim yang telah berkontribusi dalam penelitian ini.

\section{Daftar Pustaka}

[1]. STEM-ISI Impianti S.r.I. "Technical Manual No. 1516/GB/13 CE33 Electronic Process Control, Genoa," Italy, 2014, pp. 7-14.

[2]. National Instruments. PID Theory Explained. Available:

www.experimentationlab.berkeley.edu [Juni 15, 2017].

[3]. Curtis D. Johnson. "Process Control Instrumentation Technology," 8nd ed., 2014, GateHarlow, pp. 1-14.

[4]. GEFRAN spa. "Manual book Gefran $80168 F$ MSW GF eXpress, Provaglio d'Iseo," Italy, 2017, pp. 6-33.

[5]. Endang Wijaya. (2012, Feb). "Sistem kontrol motor dc berbasis labview dengan menggunakan rotary encoder sebagai sensor kecepatan. "Available:

www.fdokumen.com/document/dc-motorcontrol-55c7fe6066a2a.html

[Agustus 9, 2015].

[6]. Fauzi Sri Agung, Hari Putranto. "Kendali Kecepatan Motor Dc Berbasis Labview Mengguanakan Metode PID Logic." Jurnal Teknologi Elektro dan Kejuruan Teknik Elektro Universitas Negeri Malang, vol. 24, Sep. 2015.

[7]. Mohammad A. K. Alia, Tariq M. Younes, Shebel A. Alsabbah. "A Design of a PID Self-Tuning Controller Using LabVIEW." Journal of Software Engineering and Applications, pp. 161-171, 2011.

[8]. Yunus A. Cengel, John M. Cimbala. Robert $\mathrm{H}$. Turner. "Fundamentals of Thermal-Fluid Sciences," 5nd Ed, McGraw-Hill Education, 2017. pp.417-621. 